\title{
Developmental Regulation of Intestinal Epithelial Hydrolase Activity in Human Fetal Jejunal Xenografts Maintained in Severe-Combined Immunodeficient Mice
}

\author{
TOR C. SAVIDGE, DAVID C. LOWE, AND W. ALLAN WALKER \\ Developmental Gastroenterology Laboratory, Combined Program in Pediatric Gastroenterology and \\ Nutrition, Massachusetts General Hospital and Harvard Medical School, Charlestown, Massachusetts \\ 02129, U.S.A. [T.C.S., W.A.W.], and Department of Cellular Physiology, The Babraham Institute, \\ Cambridge CB2 4AT, U.K. [D.C.L.]
}

\section{ABSTRACT}

biopsies. Lactase-phlorizin hydrolase was the only enzyme not to reach values recorded in pediatric brush border membranes, although activities were significantly (5.6-fold) higher than in pretransplanted fetal bowel. Human jejunal xenografts therefore demonstrate an appropriate developmental induction of brush border hydrolase activity and may represent a useful model to study trans-acting factors that promote human epithelial differentiation and function in vivo. Characterization of such agents may be of potential therapeutic use in the treatment of diseases associated with gastrointestinal immaturity, notably necrotizing enterocolitis. (Pediatr Res 50: 196-202, 2001)

\section{Abbreviations}

scid, severe-combined immunodeficient

AP, alkaline phosphatase

LPH, lactase-phlorizin hydrolase

AG, $\alpha$-glucosidase

APN, aminopeptidase-N

DPPIV, dipeptidyl peptidase IV
The small intestine comprises several major epithelial cell lineages derived from a stem cell population situated near the base of the crypts of Lieberkühn (1). Enterocytes represent the largest epithelial cell lineage generated by cell proliferation in the crypts, after which they migrate to the villus tip where the cells are eventually shed into the lumen. In the human small intestine, this process takes approximately $5 \mathrm{~d}$ and is associated with terminal cytodifferentiation of these cells (2). Apical microvillus or brush border enzyme development is an effec-

Received September 25, 2000; accepted February 8, 2001.

Correspondence and reprint requests: Tor Savidge, Ph.D., Developmental Gastroenterology Laboratory, Combined Program in Pediatric Gastroenterology and Nutrition, Massachusetts General Hospital and Harvard Medical School, 114 16th Street, Charlestown, MA 02129; e-mail savidge@helix.mgh.harvard.edu

Supported in part by NIH grants RO1-HD31852, PO1-DK33506, P30-DK40561, and R37-HD12437. tive marker of enterocyte cytodifferentiation. For example, hydrolases are the most abundant integral membrane proteins of the microvillus apical membrane and are responsible for a number of reactions that are important in the digestion, transport, and absorption of nutrients $(3,4)$. These include the terminal digestion of dietary carbohydrates by disaccharidases, and cleavage of peptides and phosphate groups by peptidases and phosphatases, respectively.

Regulation of brush border hydrolase activity has been investigated in a number of different models $(4,5)$. These studies have demonstrated that numerous exogenous and physiologic factors, e.g. nutrients, growth factors, and glucocorticosteroids, can exert control over the transcription, translation, and activity of hydrolases along the different regions or cephalocaudal axis of the gastrointestinal tract $(6-8)$. Strict control 
mechanisms also operate locally within intestinal sites that express high levels of hydrolase activity, e.g. disaccharidase expression in duodenum and jejunum (9-11). Notably, distinct transcription and translation events are detected along the crypt-villus axis, which confine hydrolase activity largely to the villus compartment where the enterocytes perform their respective digestive and absorptive functions (12).

Extensive regulation of intestinal brush border hydrolase activity is also associated with the development of the gastrointestinal tract and has served as a useful tool to delineate the functional ontology of the small intestine $(5,13,14)$. For example, rodents display two major phases of functional development. Late in gestation, the first phase is associated with morphologic development of the small intestine. During this time abundant gene expression and translation is found to develop the ability of the tissue to produce hydrolases, e.g. $\mathrm{LPH}$, and other proteins, e.g. intestinal or hepatic fatty acid binding proteins and apolipoproteins, required for the efficient digestion and absorption of milk components during the suckling period (5). The second maturational phase occurs with the onset of weaning during the third postnatal week. This period is associated with a dramatic increase in the expression of genes required for the digestion and absorption of carbohydrate in solid food, e.g. sucrase-isomaltase, trehalase, maltaseglucoamylase, and the fructose transporter $\operatorname{GLUT5}(4,5)$. Coincident with this second maturational phase, hydrolase activity previously required during the suckling period is drastically attenuated, e.g. LPH activity is diminished because of reduced gene expression and protein translation, and increased enzyme turnover (15).

Gastrointestinal development in humans is profoundly different from that in rodents. Morphologic and functional maturation largely occurs in utero in the absence of the exogenous luminal stimulation of postnatal life (16). By 4 wk of gestation, the human fetal small intestine is recognized as a simple tube, with villi and crypts appearing by 8 and $10 \mathrm{wk}$, respectively. By 10 wk of gestation, glucose transport and peptidases are found, with active amino acid transport and hydrolase activity detectable by 12 wk of gestation. By 24 wk of gestation, hydrolase activity is comparable to newborn levels, although complete structural and functional maturity of the small intestine is not evident until after 38 wk of gestation (4, 17-19). Developmental studies of late second and third trimester intestinal tissues are severely compromised by the limited availability of such tissues for study. In addition, long-term in vitro studies are not yet feasible using older fetal intestinal tissues. With the increased incidence of premature births and survival of infants as young as 22 to $25 \mathrm{wk}$ of gestation, these preterm infants are prone to developing acute gastrointestinal disease, especially necrotizing enterocolitis. This disorder has been linked to gastrointestinal immaturity, in which it has been suggested that the bowel is prone to infection, and demonstrates accentuated mucosal immune reactions to the commensal gut microflora (20). It is therefore important to develop suitable in vivo model systems to examine developmental profiles for late-gestational stage human fetal intestine $(>22$ wk of gestation) and test whether abnormal mucosal immune responses to bacterial components are associated with tissue immaturity.

Human intestinal xenografts have previously been used to study developmental aspects of human gastrointestinal ontology (21-24), and bacterial-induced mucosal inflammation (2527). These studies demonstrated that after $10 \mathrm{wk}$ of xenotransplantation, morphologic development of 13.5-wk gestational age human fetal intestine was profound, and closely resembled pediatric bowel. A degree of functional maturity was also demonstrated as brush border AP activity showed clear proximal-to-distal gradients that were dependent on the region of fetal tissue used for xenografting (23). Highest levels of AP activity were measured in duodenal and jejunal fetal xenografts, where enzyme activity was comparable to that in pediatric duodenal biopsies. However, AP is differentially regulated when compared with other intestinal epithelial hydrolases during childhood enteropathy (28) and malignancy (29).

This study therefore investigated whether the developmental induction of AP activity in human fetal jejunal xenografts is also typically found for other hydrolases. In particular, we characterized disaccharidase and peptidase activities as these are important and sensitive markers of intestinal maturity, and are differentially regulated during gestation. We measured the spatio-temporal activity of the disaccharidases LPH and AG, the peptidases APN and DPPIV, and AP in proximal fetal, xenograft, and pediatric small bowel. AP, APN, and AG activities were greatly enhanced during xenograft development, thereby accurately recapitulating the ontogeny for these enzymes in utero. DPPIV levels remained at a relatively constant level in all tissues studied, whereas LPH activity, although showing significant elevation after xenografting of fetal jejunum, never reached values measured in pediatric duodenal biopsies. These studies further demonstrate the feasibility of using murine intestinal xenograft models to critically examine human gastrointestinal development as has been shown in previous studies (21-24).

\section{METHODS}

Materials. All materials (reagent or molecular grade) were obtained from Sigma Chemical Co. (St. Louis, MO, U.S.A.), unless otherwise stated.

Xenotransplantation of human fetal jejunum in scid mice. Human fetal jejunum was obtained from the MRC Tissue Bank, Royal Marsden Hospital, London, U.K. [eight samples; median age, $13.3 \mathrm{wk}$ (range, 10.3-15.9 wk) of gestation, as assessed by crown-rump length] after therapeutic abortion. Procurement and procedures involving xenografting of human fetal tissues into C.B-17 scid mice were performed with full approval from local ethics committees and in accordance with the Home Office guidelines specified in the Polkinghorne Report (29). Before transplantation, fetal jejunal tissues were washed twice in ice-cold serum-free Dulbecco's Modified Eagle's Medium. Jejunum was taken between 40 and $60 \%$ distance from pylorus to ileocecal junction, distal to the ligament of Treitz.

Xenotransplantation of fetal intestinal tissues into scid mice was performed as previously described (23). Intact segments of 
fetal bowel (2-3 cm lengths) were transplanted s.c. onto the back of 6- to 8-wk-old female and male mice. Scid mice were maintained in negative-pressure isolators supplied with HEPA filters and had access to sterilized food (Labsure, K\&K Greef Ltd., Croyden, U.K.) and water ad libitum. Jejunal xenografts were harvested $10 \mathrm{wk}$ after transplantation and were compared with corresponding segments prepared from the same fetal tissue used for surgery. Xenograft tissues were also compared with histologically normal pediatric duodenal biopsies [eight samples; 5F:3M; median age, 34 mo (range, 4-41 mo)] obtained from routine investigative procedures performed at the Queen Elizabeth Hospital for Children, London, U.K., with fully informed consent and local ethical committee approval. For routine analysis of fetal, xenograft, and pediatric intestinal morphology, tissues were fixed in $10 \%$ phosphate-buffered formal saline ( $\mathrm{pH} 7.2)$ for $24 \mathrm{~h}$ and embedded in paraffin wax using routine procedures. Sections ( $5 \mu \mathrm{m}$ thick) were deparaffinized and stained with hematoxylin and eosin or periodic acid-Schiff stain.

Quantitative enzyme cytochemistry. For cytochemical determination of epithelial brush border enzyme activity, $10-\mu \mathrm{m}$ frozen sections of fetal, pediatric, and xenograft intestine were incubated under initial rate conditions at $37^{\circ} \mathrm{C}$, with an appropriate artificial substrate as has been described previously (28, 30-33). When preparing assays for AP, APN, and AG, tissue sections were prefixed in formal calcium ( $\mathrm{pH}$ 6.0), consisting of $1.1 \% \mathrm{CaCl}_{2}$ and $3.8 \%$ formaldehyde in deionized water, for $10 \mathrm{~min}$ at $4{ }^{\circ} \mathrm{C}$ before the enzyme reactions $(28,33)$. When determining LPH and DPPIV activity, unfixed freshly cut frozen sections were used (28).

AP activity in intestinal xenografts was measured by the dephosphorylation of $0.5 \mathrm{mM}$ naphthol-AS-BI-phosphate in Tris- $\mathrm{HCl}$ buffer ( $\mathrm{pH} 8.3$ ), coupled to the dye Fast Blue B. AP activity produced a blue-purple precipitate on the brush borders of villi (Fig. $1, A-C$ ), after a 90 -s incubation at $37^{\circ} \mathrm{C}$. APN activity in intestinal xenografts was measured by cleavage of $0.7 \mathrm{mM}$ L-alanine-4-methoxy- $\beta$-naphthylamide in $0.1 \mathrm{M}$ sodium acetate buffer ( $\mathrm{pH}$ 6.5), coupled to the dye Fast Blue B. APN activity produced a reddish blue precipitate on the brush borders of the villi (Fig. 1, $D-F$ ), after a 3.5-min incubation at $37^{\circ} \mathrm{C}$. Neutral AG activity, an indicator of sucrase-isomaltase and maltase glucoamylase, as well as lysosomal hydrolases (33), was measured in intestinal xenografts by the cleavage of $6 \mathrm{mM}$ 2-naphthyl- $\alpha$-D-glucopyranoside in $0.1 \mathrm{M}$ citratephosphate buffer ( $\mathrm{pH}$ 6.0), coupled with the dye hexazonium$p$-rosaniline. AG activity produced an orange-mauve precipitate within the villus epithelium (Fig. 1, $G-I$ ) after a 5-min incubation at $37^{\circ} \mathrm{C}$. LPH activity was measured in intestinal xenografts by the cleavage of $1.09 \mathrm{mM} 5$-bromo-4-chloro-3indolyl- $\beta$-D-fucopyranoside in $0.1 \mathrm{M}$ citrate-phosphate buffer (pH 6.0) containing $0.05 \mathrm{M}$ potassium ferricyanide and $0.05 \mathrm{M}$ potassium ferrocyanide. LPH activity produced a blue precipitate within the villus epithelium after a 7-min incubation at $37^{\circ} \mathrm{C}$ (Fig. $1, J-L$ ). DPPIV activity was measured in intestinal xenografts by the cleavage of $3 \mathrm{mM}$ Gly-Pro-4-methoxy-2naphthylamine in $0.1 \mathrm{M}$ phosphate buffer ( $\mathrm{pH} 7.5$ ), coupled with the dye Fast Blue B. DPPIV activity produced a bluepurple precipitate within the villus epithelium after a 6-min incubation at $37^{\circ} \mathrm{C}$ (Fig. 1, $M-O$ ). All enzyme reactions were performed under initial rate conditions as described previously (28).

Quantitative measurements of enzyme activity were performed on a Leitz MPV-3 microdensitometer (Milton Keynes, Bucks, U.K.), at a final magnification of $\times 400$. Sequential absorbance readings at the respective monochromatic wavelengths, i.e. 550, 450, 480, 660, and $480 \mathrm{~nm}$ for $\mathrm{AP}$, $\mathrm{APN}, \mathrm{AG}$, $\mathrm{LPH}$, and DPPIV, respectively, were taken at $16-\mu \mathrm{m}$ increments along the crypt-villus axis (using a scanning window size of $4 \times 4 \mu \mathrm{m}$ ), starting from the crypt-villus junction and ending at the villus tip. Values from each incremental position from a minimum of five well-orientated villi were averaged to provide final profiles for enzyme activity.
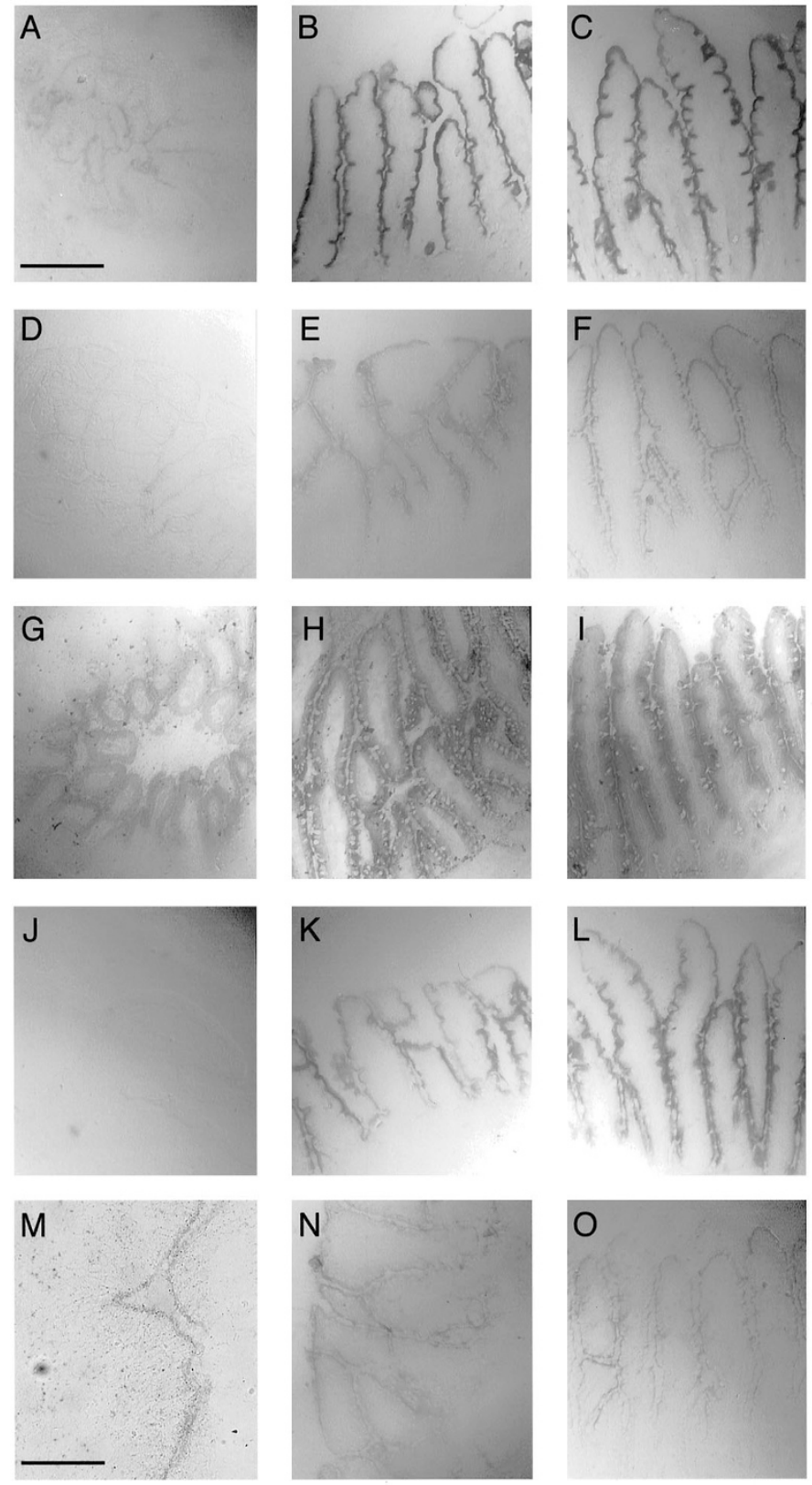

Figure 1. Enzyme cytochemistry showing AP $(A-C), \mathrm{APN}(D-F), \mathrm{AG}(G-I)$, LPH $(J-L)$, and DPPIV $(M-O)$ activities in human fetal $(A, D, G, J, M)$, xenograft $(B, E, H, K, N)$, and pediatric $(C, F, I, L, O)$ intestine, respectively. Scale bars represent $100 \mu \mathrm{m}(A-L, N, O)$ and $25 \mu \mathrm{m}(M)$. 
Statistics. Results are presented as the mean \pm SEM. Statistical comparisons were made using the Welsh test to account for unpooled variance, and the nonparametric Mann-Whitney $U$ test for ranks using MINITAB statistical software (Minitab Inc., State College, PA, U.S.A.). Differences with a $p<0.05$ were considered significant.

\section{RESULTS}

Human fetal intestinal xenografts (derived from 13.5-wk gestational age tissues) regenerated to form a highly developed mucosa after ectopic transplantation into scid mice. As we have described previously $(23,24)$, this mucosa was lined with terminally differentiated enterocytes that possessed a highly developed glycocalyx, apical zonula occludens, and brush border membrane with uniform microvilli. Although the xenografts formed a differentiated mucosa, these showed a degree of morphologic variability within individual grafts, which primarily involved uneven villus height in the samples analyzed. Therefore, to 1) quantify subtle spatio-temporal alterations in brush enzyme activity along the crypt-villus axis, and 2) exclude the inherent problems of measuring mucosal enzyme activities in tissues with grossly different morphologies, i.e. fetal versus xenograft versus pediatric jejunum, we used a well-described scanning microdensitometric method to quantify epithelial-derived enzyme activities in five morphologically normal crypt-villus units $(28,30-35)$. Typical colored reaction products for fetal, xenograft, and pediatric AP, APN, AG, LPH, and DPPIV activities are shown in Figure 1.

By using this approach, we corroborated our previous finding that AP activity is significantly induced in fetal jejunum (9.8-fold; $p<0.001$ ) after xenotransplantation of identical tissues for $10 \mathrm{wk}$ (Fig. 2A). Xenograft brush border membrane contained a similar level of AP activity as normal pediatric duodenal samples, and showed a similar distribution gradient along the crypt-villus axis (Fig. 3A). AP activity was at its lowest at the base of pediatric villi and increased as cells migrated toward the mid-villus area where it reached a plateau. In xenograft villi, AP activity was higher at the base where it increased rapidly toward the mid-villus area and then declined toward the villus tip. The highly differentiated state of these cells is probably related to the slower epithelial proliferation and cell migration rates recorded in xenograft small bowel (24, 27). Induction of enzyme activity along the crypt-villus axis is partly dependent on epithelial migration rates (36).

Relatively low enzyme activities were also detected for APN (Fig. 2B) and AG (Fig. 2C) in pretransplanted fetal tissues, with little or no enzyme activity being detectable for LPH (Fig. $2 D$ ). All enzyme activities, apart from DPPIV (Fig. 2E), were significantly elevated in jejunal xenografts by $10 \mathrm{wk}$ after transplantation. Mean levels of APN activity and distribution along the crypt-villus axis in xenografts and pediatric samples followed a similar pattern to that seen for AP (Fig. 3B). Both sets demonstrated a similar gradient of activity, reaching a maximal level just below the mid-villus area and declining toward the tips of the villi. APN activity along the brush border membrane of pretransplanted fetal intestine was higher than that for AP activity and probably reflects the earlier appearance of this enzyme during human intestinal ontogenesis $(12,13)$.

AG represents a family of enzymes that includes sucraseisomaltase and maltase glucoamylase, as well as lysosomal hydrolases, that are essential for the breakdown of glycogen, sucrase, maltose, isomaltose, and trehalase (32). AG levels in jejunal xenografts and in normal pediatric duodenum were very similar both in terms of activity and distribution gradient along the crypt-villus axis (Fig. 3C). Levels of AG activity in fetal samples were approximately $18 \%$ of those in either pediatric or xenograft samples. LPH activity was also significantly induced in fetal jejunal samples after xenografting. Activity was barely detectable in fetal jejunum. Although this showed a 5.6-fold elevation after xenografting, this value was still significantly lower than values recorded in pediatric samples (22.6-fold increase). A similar distribution gradient was observed for LPH activity in xenograft and pediatric samples, with a gradual increase in activity toward the mid-villus region followed by a sharp diminution toward the villus tip (Fig. 3D). DPPIV ac-

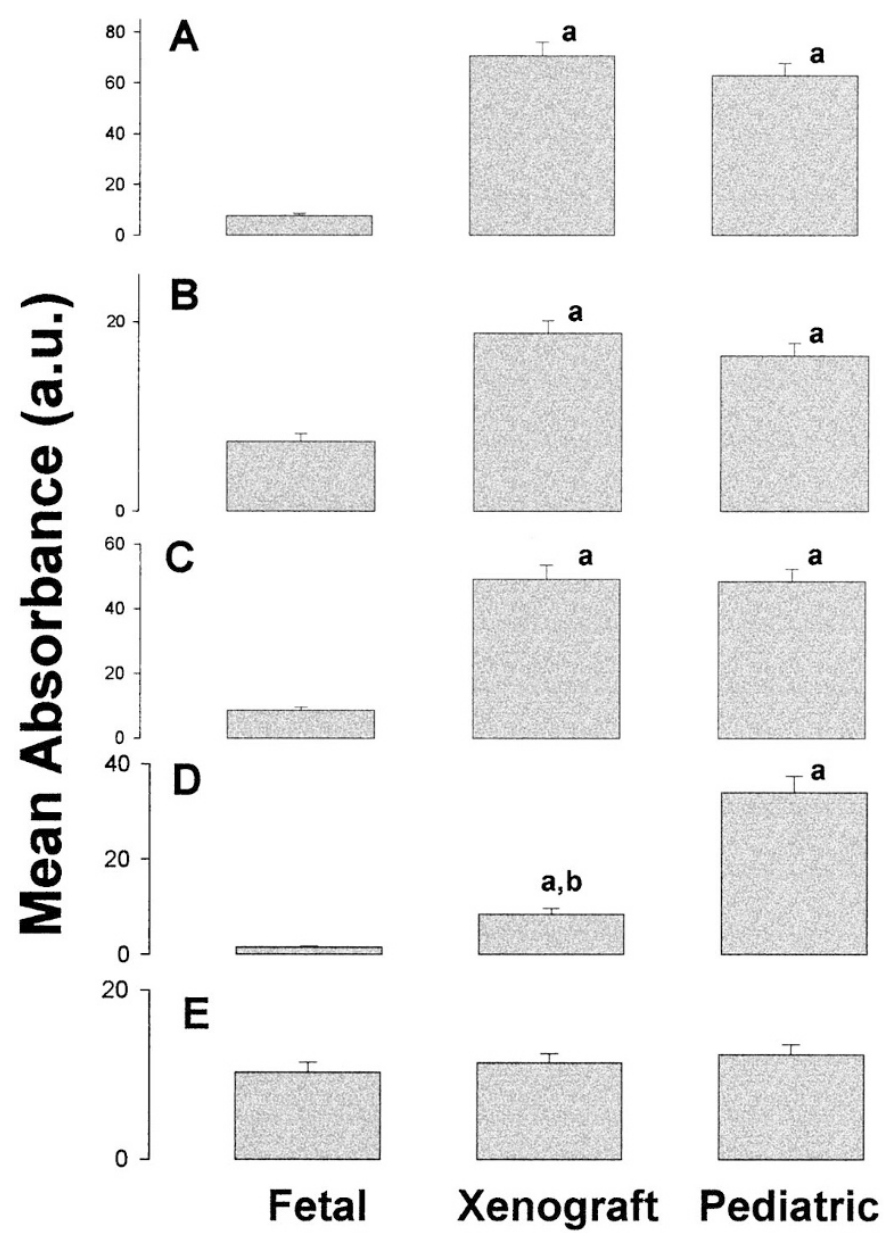

Figure 2. Enzyme cytochemistry showing the mean absorbance for AP $(A)$, APN $(B), \operatorname{AG}(C), \mathrm{LPH}(D)$, and DPPIV $(E)$ activity in fetal $(n=8)$, xenograft $(n=8)$, and pediatric $(n=8)$ intestine (a indicates significant difference between fetal and xenograft or pediatric bowel; b indicates significant difference between xenograft and pediatric bowel; results are mean + SEM). Mean group values were calculated from a range of 560-1200 individual incremental absorbance readings measured along the crypt-villus axis as shown in Figure 3. 
tivity was fairly uniformly expressed in fetal, xenograft, and pediatric tissues (Fig. 2E), and was detected in fetal jejunum as early as $10.3 \mathrm{wk}$ of gestation (Fig. $1 M$ ). Although its expression increased after transplantation, this was not significantly different from that recorded in fetal tissues. DPPIV activity tapered off slightly toward the villus tip (Fig. $3 E$ ).

\section{DISCUSSION}

A major aim of this study was to assess the suitability of human intestinal xenografts to accurately recapitulate human gastrointestinal development during the late second and third trimester (24). Little information is currently available regarding gastrointestinal ontogeny and function during this developmental stage, and establishing a suitable "humanized" animal model will not only allow critical evaluation of diseases associated with immaturity, such as necrotizing enterocolitis, but may also provide a suitable tool to test novel forms of prevention or therapy at a preclinical level. Using a panel of five epithelial hydrolases that are switched on at different stages during ontogeny, we measured their developmental expression profiles in jejunal xenografts and compared these to pediatric enzyme levels measured in duodenal biopsies.

Quantitative cytochemistry permitted the determination of enzyme activity profiles along the length of the crypt-villus axis without disrupting the spatial relationships of the migrating enterocytes. This approach therefore provides a clearer understanding of how these cells adjust their program of

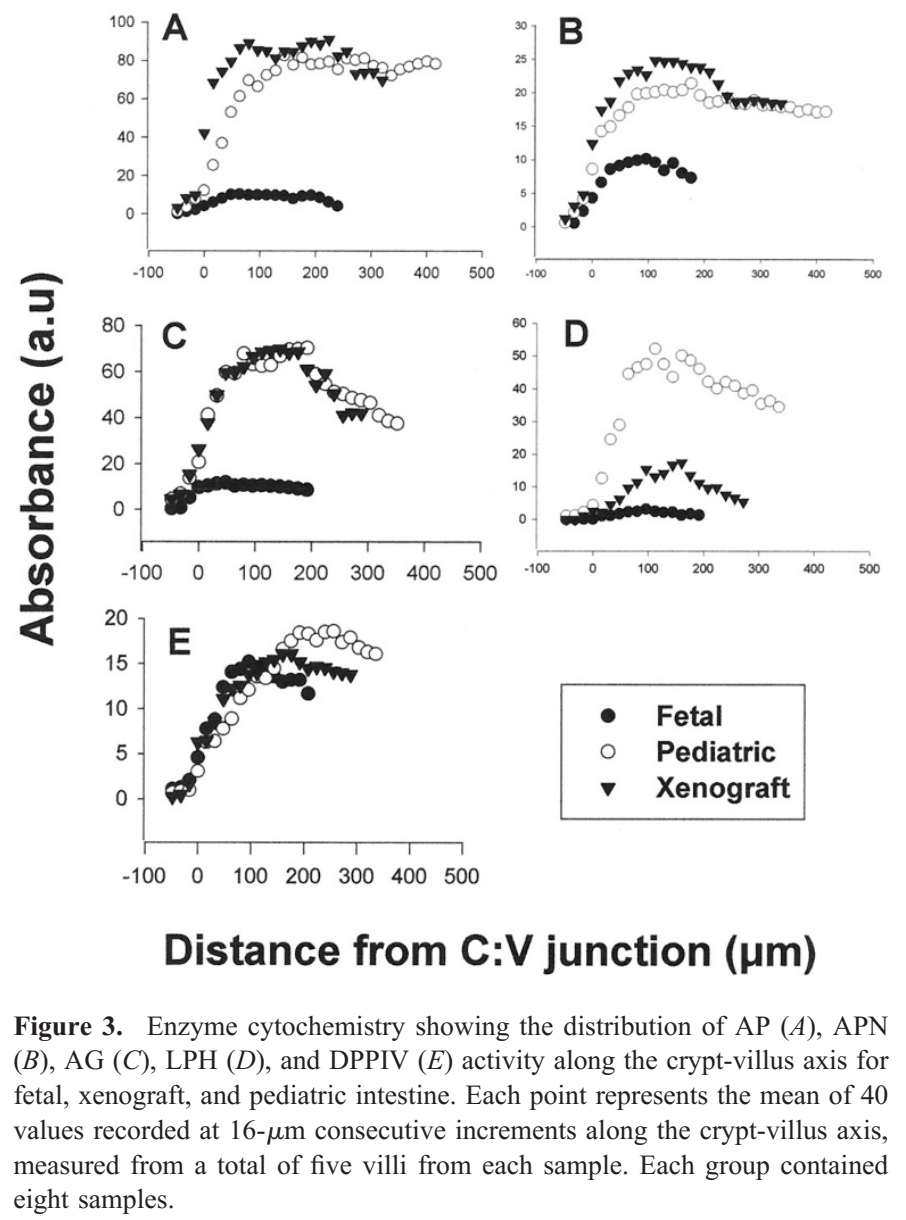

development to adapt to changes in their immediate microenvironment. Such adaptation may involve different combinations of several events, including a shortening of the time needed to begin expressing brush border hydrolases, an increase in the rate at which the hydrolases are expressed, and an extension of the time during which net appearances of these hydrolases can be seen to increase. Using this approach we demonstrated 1) appropriate spatio-temporal regulation of enzyme activity along the xenograft crypt-villus axis, and 2) levels of enzyme activity in xenografts that were comparable to pediatric bowel.

These results therefore demonstrate that after $10 \mathrm{wk}$ of transplantation, early gestational age fetal intestine (13.5 wk) has the capacity to develop brush border enzyme activities that are significantly higher than in pretransplanted intestinal tissues and that probably reflect activities encountered during late second or third trimester as enzyme activities may develop to pediatric levels in utero $(4,5)$. Minor differences were observed with LPH activity. Although this was significantly increased in xenograft as compared with pretransplanted fetal bowel, these were significantly lower than values measured for pediatric biopsies. A number of reasons could explain these findings, for example, the age of the pretransplanted tissue is too young to develop significant LPH activity, or the grafting duration is too short (equivalent to approximately $24 \mathrm{wk}$ of gestation) to develop significant expression as LPH activity is markedly induced during the second half of the third trimester $(4,13,28,37)$. Another possible explanation could be that LPH activity is significantly suppressed in xenografts because of enhanced local immune reactions. Previous studies have demonstrated that LPH activity is significantly and differentially reduced in sites of enhanced local immune activity, i.e. Peyer's patches (35), or during immunopathology of the small bowel (28). DPPIV activity was expressed at fairly uniform levels in all three types of tissue examined and served as a suitable control as this enzyme is uniformly expressed after $10 \mathrm{wk}$ of gestation.

Although this represents the first study to describe in detail the development of brush border enzyme activity in human intestinal xenografts, the concept of using ectopic grafts to study gastrointestinal enzyme ontogeny is not a novel one. A number of studies have demonstrated the feasibility for ectopic grafting of gastrointestinal tissues into adult recipient hosts, although these have primarily used syngeneic rodent tissues $(38-41)$. Transplanted intestine rapidly vascularizes and grows into a characteristic tissue that retains an ability to express appropriate brush border enzyme levels, e.g. lactase, sucrase, and maltase, and to absorb nutrients, e.g. glucose, glycine, and oleic acid. Ferguson et al. (38) isografted embryonic d 19 fetal mouse jejunum under the kidney capsule of adult CBA mice and demonstrated that the developmental changes in brush border lactase and sucrase activity that occur normally during weaning in the third postnatal week were accurately recapitulated in the isografts. This led to the concept that one or more timing mechanisms are intrinsic to the intestinal mucosa, thereby providing a spatial and temporal "memory," enabling appropriate tissue development in the absence of luminal signals and systemic hormones encountered during late gestation 
and the early postnatal period. These findings were later confirmed in rats, and a regional distribution in sucrase activity was identified along the tract of fetal isografts $(39-41)$. Importantly, parallel findings have demonstrated that fetal tissue becomes committed to late expression before the invagination of mesenchymal components that provide instructive information to the endoderm (42). These early graft findings also demonstrated that maltase and AP develop normally, but LPH expression is down-regulated in fetal isografts (36), as we have demonstrated in the present work for human xenografts. The importance of these experiments lies in their ability to distinguish locally programed changes in enterocyte cytodifferentiation from those arising from changes in the hormonal status or food intake of suckled animals.

It is generally accepted that enterocyte cytodifferentiation takes place earlier during fetal development in human as compared with rat intestine, and that in the latter, expression of sucrase is largely controlled through an intrinsic timing mechanism. The present work demonstrates that maturation of human intestinal epithelial hydrolase activity is also triggered by intrinsic timing mechanisms of the intestinal mucosa. Apart from AP being one of the first enzymes to appear in both human and rat intestine, there is little further correlation in the ontogeny of hydrolase activity. It may be concluded from these comparisons that time-controlled expression of some and possibly all human intestinal hydrolases occurs during development $(4,37,42)$, but that more work is needed to test the generality of this statement. For example, in addition to time, other factors may be required to complete developmental programs for enzymes such as LPH in the human preterm infant. High surges of glucocorticoids have the ability to elicit precocious maturation in a number of experimental animal models $(5,43)$. Signals derived from luminal amniotic fluid may also contribute to the development of enzyme activities in utero (44), possibly mediated by specific growth factors. Organ culture studies of human fetal intestine in defined tissue culture medium have demonstrated differential effects of hydrocortisone, insulin, and epidermal growth factor in regulating hydrolase expression, apolipoprotein and lipoprotein secretion, and cellular proliferation (45-49). However, the implication of these important findings to tissue development in utero are somewhat limited by the current inability to perform long-term in vitro experiments on late-gestational fetal intestine. These pathways may now be tested in vivo using the intestinal xenograft model as the grafts form a continuous lumen that allows inoculation with bioactive molecules via s.c. injection (50).

In summary, human intestinal xenografts show an appropriate spatio-temporal induction of epithelial hydrolase activity (with the possible exception of LPH) after xenografting fetal intestine and may therefore represent a useful in vivo system to model preterm human gastrointestinal development and function.

Acknowledgment. The authors thank Dr. Alan Phillips (Royal Free Hospital, London, U.K.) for providing pediatric biopsies.

\section{REFERENCES}

1. Cheng H, Leblond CP 1974 Origin, differentiation and renewal of the four main epithelial cell types in the mouse small intestine V. Unitarian theory of the origin of the four epithelial cell types. Am J Anat 141:537-562

2. Klein RM, McKenzie JC 1983 The role of cell renewal in the ontogeny of the intestine. I. Cell proliferation patterns in adult, fetal, and neonatal intestine. J Pediat Gastroenterol Nutr 2:10-43

3. Louvard D, Kedinger M, Hauri HP 1992 The differentiating intestinal epithelial cell: establishment and maintenance of functions through interactions between cellular structures. Annu Rev Cell Biol 8:157-195

4. Traber PG 2000 Development of brushborder enzyme activity. In: Sanderson IR, Walker WA (eds) Development of the Gastrointestinal Tract. BC Decker Inc, Hamilton, pp 103-122

5. Henning DJ, Rubin DC, Shulman RJ 1994 Ontogeny of the intestinal mucosa. In: Johnson LR (ed) Physiology of the Gastrointestinal Tract, 3rd Ed. Raven Press, New York, pp 571-610

6. Kodolvsky O 1981 Developmental, dietary and hormonal control of intestinal disaccharidases in mammals (including man). In: Randle PJ, Steiner DF, Whelan WJ (eds) Carbohydrate Metabolism and Its Disorders. Academic Press, London, pp 481-522

7. Menard D 1989 Growth-promoting factors and the development of the human gut. In: Lebenthal E (ed) Human Gastrointestinal Development. Raven Press, New York, pp 545-559

8. Nanthakumar NN, Henning SJ 1993 Ontogeny of sucrase-isomaltase gene expression in rat intestine: responsiveness to glucocorticoids. Am J Physiol 264:G306-G311

9. Freund JN, Duluc I, Raul F 1991 Lactase expression is controlled differently in the jejunum and ileum during development in rats. Gastroenterology 45:489-497

10. Maiuri L, Rossi M, Raia V, D'Auria S, Swallow D, Quaroni A, Auricchio S 1992 Patchy expression of lactase protein in adult rabbit and rat intestine. Gastroenterology 103:1739-1746

11. Norén O, Dabelsteen E, Høyer PE, Olsen J, Sjöström H, Hansen GH 1989 Onset of transcription of the aminopeptidase N (leukemia antigen CD 13) gene at the crypt/ villus transition zone during rabbit enterocyte differentiation. FEBS Lett 259:107-112

12. Traber PG, Yu L, Wu GD, Judge TA 1992 Sucrase-isomaltase gene expression along crypt-villus axis of human small intestine is regulated at level of mRNA abundance. Am J Physiol 262:G123-G130

13. Montgomery RK, Grand RJ 1992 Developmental regulation of the brush border hydrolase lactase. J Pediatr Gastroenterol Nutr 15:215-217

14. Auricchio S, Sebastio G 1989 Development of disaccharidases. In: Lebenthal E (ed) Human Gastrointestinal Development. Raven Press, New York, pp 451-470

15. Tsuboi KK, Kwong LK, Sunshine P, Castillo RO 1992 Mechanism of maturational decline of rat intestinal lactase-phlorizin hydrolase. Biochem J 282:107-113

16. Montgomery RK, Mulberg AE, Grand RJ 1999 Development of the human gastrointestinal tract: twenty years of progress. Gastroenterology 116:702-731

17. Dahlqvist A, Lindberg $T 1966$ Development of the intestinal disaccharidase and alkaline phosphatase activities in the human fetus. Clin Sci 30:517-528

18. Auricchio S, Stellato A, De Vizia B 1981 Development of brush border peptidases in human and rat small intestine during fetal and neonatal life. Pediatr Res 15:991-995

19. Moriyama IS 1986 Development of fetal organs and adaptation to extrauterine life. Nippon Sanka Fujinka Gakkai Zasshi 38:1227-1237

20. Israel EJ 1996 Necrotizing enterocolitis. In: Walker WA, Durie PR, Hamilton JR (eds). Pediatric Intestinal Disease, 2nd Ed. Mosby, St. Louis, pp 750-761

21. Savidge TC, Morey AL, Ferguson DJP, Fleming KA, Shmakov AN, Phillips AD 1995 Human intestinal development in a severe-combined immunodeficient xenograft model. Differentiation 58:361-371

22. Savidge TC 2000 Ectopic transplantation techniques for evaluating gastrointestinal development. In: Sanderson IR, Walker WA (eds) Development of the Gastrointestinal Tract. BC Decker Inc, Hamilton, pp 307-318

23. Friedberg JS, Ryan DP, Driscoll SG, Folkman J 1985 Human small bowel transplants into athymic mice and rats. Surg Forum 36:375-378

24. Winter HS, Hendren RB, Fox CH, Russel GJ, Perez-Atayde A, Bhan AK, Folkman J 1991 Human intestine matures as nude mouse xenografts. Gastroenterology 100:89-98

25. Huang GTJ, Eckmann L, Savidge TC, Kagnoff MF 1996 Infection of human intestinal epithelial cells with invasive bacteria upregulates apical intercellular adhesion molecule-1 (ICAM-1) expression and neutrophil adhesion. J Clin Invest 98:572-583

26. Eckmann L, Stenson WF, Savidge TC, Lowe DC, Barrett KE, Fierer J, Smith JR, Kagnoff MF 1997 Role of intestinal epithelial cells in the host secretory response to infection with invasive bacteria: bacterial entry induces epithelial prostaglandin $\mathrm{H}$ synthase-2 expression, and prostaglandin $\mathrm{E}_{2}$ and $\mathrm{F}_{2 \alpha}$ production. $\mathrm{J}$ Clin Invest 100:296-309

27. Savidge TC, Shmakov AN, Walker-Smith JA, Phillips AD 1997 Intestinal proliferation and infection in childhood. In: Halter F, Winton D, Wright NA (eds). The Gut as a Model in Cell and Molecular Biology. Kluwer Academic Publishers, London, pp $110-120$

28. Phillips AD, Smith MW, Walker-Smith JA 1988 Selective alteration of brush-border hydrolases in intestinal diseases in childhood. Clin Sci 74:193-200

29. Harris H 1990 The human alkaline phosphatases: what we know and what we don't know. Clin Chim Acta 186:133-150

30. Polkinghorne Report 1989 Review of the Guidance on the Research Use of Fetuses and Fetal Material. Category M 762, Her Majesty's Stationary Office, London, pp 1-9

31. Nordstrom C, Dahlqvist A 1973 Quantitative distribution of some enzymes along the villi and crypts of human small intestine. Scand J Gastroenterol 8:408-416

32. Grossrau R 1980 Conventional techniques for membrane-bound enzymes: trends in enzyme histochemistry and cytochemistry. Ciba Found Symp 73:67-80 
33. Gutschmidt S, Emde C, Riecken EO 1980 Quantification of $\alpha$-glucosidases along the villus of the small intestine in man. Histochemistry 67:85-97

34. Gutschmidt S, Gossrau R 1981 A quantitative histochemical study of dipeptidylpeptidase IV (DPPIV). Histochemistry 73:285-304

35. Savidge TC, Smith MW, Mayel-Afshar MS, Collins A, Freeman TC 1994 Selective regulation of epithelial gene expression in rabbit Peyer's patch tissue. Eur J Physiol 428:391-399

36. Smith MW 1991 Cell biology and molecular genetics of enterocyte differentiation. Curr Top Membr 39:154-179

37. Sebastio G, Hunziker W, O’Neill B, Malo C, Menard D, Auricchio S, Semenza G 1987 The biosynthesis of intestinal sucrase-isomaltase in human embryo is most likely controlled at the level of transcription. Biochem Biophys Res Commun 149:830-839

38. Ferguson A, Gerskowitch VP, Russel RI 1973 Pre- and post-weaning disaccharidase patterns in isografts of fetal mouse intestine. Gastroenterology 64:292-297

39. Kendall K, Jumawan J, Koldovsky O, Krulich L 1977 Effect of the host hormona status on development of sucrase and acid $\beta$-galactosidase in isografts of rat small intestine. J Endocrinol 74:145-146

40. Kendall K, Jumawan J, Koldovsky O 1979 Development of jejunoileal differences of activity of lactase, sucrase and acid $\beta$-galactosidase in isografts in fetal rat intestine. Biol Neonate 36:206-214

41. Montgomery RK, Sybicki MA, Grand RJ 1981 Autonomous biochemical and morphological differentiation in fetal rat intestine transplanted at 17 and 20 days of gestation. Dev Biol 87:76-84
42. Rubin DC, Swietlicki E, Roth KA, Gordon JI 1992 Use of fetal intestinal isografts from normal and transgenic mice to study the programming of positional information along the duodenal-to-colonic axis. J Biol Chem 267:15122-15133

43. Van Beers EH, Rings EH, Taminiau JA, Heymans HS, Einerhand AW, Dekker J, Buller HA 1998 Regulation of lactase and sucrase-isomaltase gene expression in the duodenum during childhood. J Pediatr Gastroenterol Nutr 27:37-46

44. Adrian TE, Soltesz G, MacKenzie LZ, Bloom SR, Aynsley-Green AL 1995 Gastrointestinal and pancreatic hormones in the human fetus and mother at 18-21 weeks of gestation. Biol Neonate 67:47-53

45. Mulvihill SJ, Stone MM, Debas HT, Fonkalsrud EW 1985 The role of amniotic fluid in fetal nutrition. J Pediatr Surg 20:668-672

46. Menard D, Arsenault P, Pothier P 1988 Biologic effects of epidermal growth factor in human fetal jejunum. Gastroenterology 94:656-663

47. Villa M, Menard D, Semenza G, Mantei N 1992 The expression of lactase enzymatic activity and mRNA in human fetal jejunum: effect of organ culture and of treatment with hydrocortisone. FEBS Lett 301:202-206

48. Loirdighi N, Menard D, Delvin D, Levy E 1997 Selective effects of hydrocortisone on intestinal lipoprotein and apolipoprotein synthesis in the human fetus. J Cell Biochem 66:65-76

49. Menard D, Corriveau L, Beaulieu JF 1999 Insulin modulates cellular proliferation in developing human jejunum and colon. Biol Neonate 75:143-151

50. Savidge TC, Shmakova A 1995 Human gastrointestinal drug delivery; an experimental chimeric approach. J Drug Target 3:71-74 